\title{
Evaluating the Efficacy of Brood Flush Counts: A Case Study in Two Quail Species
}

Author(s): Jeremy P. Orange, Craig A. Davis, R. Dwayne Elmore, Evan P. Tanner, Samuel D. Fuhlendorf and Eric T. Thacker

Source: Western North American Naturalist, 76(4):485-492.

Published By: Monte L. Bean Life Science Museum, Brigham Young University

DOI: http://dx.doi.org/10.3398/064.076.0409

URL: http://www.bioone.org/doi/full/10.3398/064.076.0409

BioOne (www.bioone.org) is a nonprofit, online aggregation of core research in the biological, ecological, and environmental sciences. BioOne provides a sustainable online platform for over 170 journals and books published by nonprofit societies, associations, museums, institutions, and presses.

Your use of this PDF, the BioOne Web site, and all posted and associated content indicates your acceptance of BioOne's Terms of Use, available at www.bioone.org/page/ terms of use.

Usage of BioOne content is strictly limited to personal, educational, and non-commercial use. Commercial inquiries or rights and permissions requests should be directed to the individual publisher as copyright holder. 


\title{
EVALUATING THE EFFICACY OF BROOD FLUSH COUNTS: A CASE STUDY IN TWO QUAIL SPECIES
}

\author{
Jeremy P. Orange ${ }^{1,3}$, Craig A. Davis ${ }^{1}$, R. Dwayne Elmore ${ }^{1}$, Evan P. Tanner ${ }^{1}$, \\ Samuel D. Fuhlendorf ${ }^{1}$, and Eric T. Thacker ${ }^{2}$
}

ABSTRACT.-Taking brood flush counts is a common sampling method that has been used for decades to estimate brood and chick survival in many gallinaceous bird species. However, brood survival estimates based upon flush counts may be biased because of low detection probabilities, occurrence of brood amalgamations, brood abandonment, and brooding adult mortality. Given that brood flush counts are still commonly used to estimate brood survival, and in some cases extrapolated to provide an estimate of chick survival, it is important to evaluate biases associated with this method. Therefore, we evaluated the use of brood flush counts to estimate brood survival of 2 gallinaceous birds: Northern Bobwhite (Colinus virginianus) and Scaled Quail (Callipepla squamata). To gain a better understanding of some of the mechanisms that may bias brood survival estimates, we radio-tagged Northern Bobwhite and Scaled Quail chicks (8-12 days old) and juveniles (4-6 weeks old) in 67 broods. We used radio-tagged chicks and juveniles to estimate and compare brood survival using 2 analysis methodologies. These methods included a telemetry method that relied upon radio-tagged chicks and a flush method that mimicked a brood flush count. In bobwhites, the brood survival estimates were higher with the telemetry-based estimate than with the flush estimate for both the 3-week chick (0.808 vs. 0.500) and 5-week juvenile (0.636 vs. 0.364$)$. In Scaled Quail, the 2 brood survival estimates were similar at the chick $(0.842$ vs. 0.789$)$ and juvenile (0.818 vs. 0.818$)$ life stages. Because Scaled Quail have lower occurrences of brooding adult mortality and brood abandonment, flush counts provided a more accurate estimate of brood survival for Scaled Quail than for bobwhites. In situations where brood abandonment or brooding adult mortality is common, researchers using flush counts to investigate gallinaceous brood survival should consider the impact that these mechanisms may have on survival estimates.

Resumen.-Los conteos visuales de puestas por medio de la técnica "flush" (haciendo volar a las aves, para poder observar su puesta) es un método de muestreo común, que ha sido utilizado durante décadas para estimar la supervivencia de la puesta y de los pollos en muchas especies de aves gallináceas. Sin embargo, las estimaciones de supervivencia de las puestas con base en estos conteos pueden estar sesgadas debido a la baja probabilidad de detección, la confusión por la amalgamación de la puesta, el abandono de puesta, y la mortalidad de adultos en el momento de la crianza. Teniendo en cuenta que este tipo de conteo de crías es comúnmente usado para estimar la supervivencia de la puesta, y en algunos casos es extrapolado para estimar la supervivencia de los pollos, es importante evaluar los sesgos asociados con esta metodología. Por tanto, evaluamos el uso de esta técnica de conteo para estimar la supervivencia de las puestas de 2 aves gallináceas: el colín de Virginia o codorniz cotuí norteña (Colinus virginianus) y la codorniz escamosa (Callipepla squamata). Para comprender mejor algunos de los mecanismos que pueden sesgar las estimaciones de supervivencia de crías, radio-etiquetamos pollos de codorniz norteña y codorniz escamosa (de 8-12 días de edad) y a individuos juveniles (de 4-6 semanas de edad) en 67 puestas. Utilizamos pollos y juveniles radio-etiquetados para estimar y comparar la supervivencia de las puestas por medio de 2 métodos de análisis. Estos métodos incluyen 'telemetría' que se basa en pollos radio-etiquetados y un método que imita al conteo "flush". En las codornices, las estimaciones de supervivencia de pollos de 3 semanas y de los juveniles de 5 semanas fueron mayores utilizando la estimación basada en telemetría, tanto en pollos (0.808 vs 0.500$)$ como en juveniles (0.636 vs 0.364). En la codorniz escamosa, las estimaciones de supervivencia de las puestas fueron similares en pollos ( 0.842 vs 0.789$)$ y en juveniles ( 0.818 vs 0.818 ). Con una mortalidad baja de adultos criando y abandonos de puesta, los conteos "flush" ofrecen una estimación más precisa de supervivencia para codornices escamosas que para codornices norteñas. En situaciones en las que ocurre abandono de puestas, o cuando la mortalidad de adultos es muy común, los investigadores que utilizan conteos "flush" para estudiar la supervivencia de las puestas de gallináceas, deben considerar el impacto que estos mecanismos pueden tener en las estimaciones de supervivencia.

Brood flush counts are commonly used by researchers to investigate both brood and chick survival in gallinaceous species (Palmer et al. 1998, Pleasant et al. 2006, Tirpak et al. 2008, Goddard and Dawson 2009, Musil and
Connelly 2009). During a brood flush count, researchers locate radio-tagged brooding adults, either diurnally or nocturnally, and then flush broods on foot or, in some cases, with the assistance of trained dogs. Data collected with

\footnotetext{
${ }^{1}$ Department of Natural Resource Ecology and Management, Oklahoma State University, Stillwater, OK 74078. ${ }^{2}$ Wildland Resources Department, Utah State University, Logan, UT 84322

${ }^{3}$ E-mail: jporange2@gmail.com
} 
this method are commonly used to verify brood presence when estimating brood survival (i.e., the probability that at least one individual survived the monitoring period; Fields et al. 2006, Pleasant et al. 2006, Matthews et al. 2011, LeBeau et al. 2014) and to count individuals within broods when generating estimates of chick survival (DeMaso et al. 1997, Pitman et al. 2006, Goddard and Dawson 2009, Pollentier et al. 2014). Survival estimates generated from flush counts are often used to investigate the factors that influence survival, compare survival rates between sites or years, and model population growth (DeMaso et al. 1997, Tirpak et al. 2006, Goddard and Dawson 2009, McNew et al. 2012).

Although brood flush counts have been used for decades, numerous issues exist with this technique. For example, the cryptic appearance and unique behavioral responses to disturbance exhibited by most gallinaceous chicks (i.e., chicks may bury themselves in thick vegetation to avoid detection or disperse away from the brooding adult) make flush counts problematic (Godfrey 1975, Dahlgren et al. 2010a). In an effort to reduce biases associated with low chick detection probabilities, many studies will instead use flush counts to generate estimates of brood survival. Brood survival estimates from flush counts are associated with less bias because they are commonly based upon the presence of at least one chick with a brooding adult, rather than the number of chicks within each brood. Despite this reduced bias, brood amalgamations are a concern when estimating brood survival, and biases related to amalgamations are unquantified for most species.

Forming amalgamations is a common brooding strategy that has been documented in most gallinaceous species (Gonzalez et al. 1998, Spears et al. 2005, Metz et al. 2006, Gregg et al. 2007, Steen and Haugvold 2009). These amalgamations can take the form of adoptions, crèching, and gang-brooding (Keppie 1977, Lott and Mastrup 1999, Faircloth et al. 2005, Brooks and Rollins 2007, Wong et al. 2009). Brood amalgamations can occur when (1) chicks are adopted by a female after becoming separated from other broods or following the death of a brooding adult, (2) chicks move from one brood to another after incidental contact, (3) a brooding adult abandons chicks to the care of another brooding adult, or (4) a group of 2 or more broods join together to form communal broods or gang-broods (Maxson 1978, Lott and Mastrup 1999, Brooks and Rollins 2007, Wong et al. 2009, Dahlgren et al. 2010b, Orange et al. 2016). Although we recognize that amalgamations formed when an individual chick or multiple chicks leave their natal brood for another brood may certainly influence brood survival estimates, our study was limited to examining the influence of brood amalgamations resulting from brood abandonment or adult mortality on brood survival estimates.

Because flush counts are commonly used to estimate brood survival and to provide an approximation of chick survival for several gallinaceous species (DeMaso et al. 1997, Fields et al. 2006, Pleasant et al. 2006, Goddard and Dawson 2009, Matthews et al. 2011), we investigated the role brood amalgamations that were facilitated by brood abandonment and mortality of brooding adults may play in affecting the accuracy of brood survival estimates. Specifically, we used radio-tagged chicks (8-28 days old) and juveniles $(>28$ days old) to investigate brood survival within a sympatric population of Northern Bobwhite (Colinus virginianus; hereafter, bobwhite) and Scaled Quail (Callipepla squamata) in western Oklahoma.

\section{METHODS \\ Study Area}

This study was conducted on the Beaver River Wildlife Management Area (WMA) in western Oklahoma. Beaver River WMA is owned and managed by the Oklahoma Department of Wildlife Conservation, and its primary objective is management for upland game and other game species. The study area is approximately 11,315 ha characterized by sand sagebrush (Artemisia filifolia) and mixedgrass riparian bottomlands with short-grass uplands. The average annual precipitation at the WMA is $54.61 \mathrm{~cm}$ with an average daytime high temperature of $35^{\circ} \mathrm{C}$ in July (Oklahoma Climatological Survey 2012).

\section{Capture and Telemetry}

This study was conducted from May through October 2013 and 2014. As part of companion research projects investigating bobwhite and 
Scaled Quail habitat use, survival, and movement, we captured adults of both species and fitted individuals weighing $>130 \mathrm{~g}$ with $7-\mathrm{g}$ necklace-style radio-transmitters (Advanced Telemetry Systems, Isanti, MN). We tracked adults 5 days each week during the nesting season, and nesting status was determined based upon whether signals were detected from the same location over consecutive days. Nesting status was verified daily at a minimum distance of $30 \mathrm{~m}$ to limit disturbance to nesting adults. Following hatching, we tracked brooding adults daily, and an initial capture event took place when broods reached 8-12 days old (chicks). Broods were located with radiotelemetry and captured using a combination of techniques described by Smith et al. (2003) and Andes et al. (2012), which were aided by use of a Thermal Imaging Camera i ${ }^{\circledR}$ (FLIR Systems, Wilsonville, OR). After capture, chicks were held for approximately $2 \mathrm{~h}$ in a collapsible cooler with a warm water bottle to prevent hypothermia. For most broods, we attempted to fit $50 \%-100 \%$ of chicks with 0.45-g suture-style transmitters (American Wildlife Enterprises, Monticello, FL) that had an expected battery life of 21-23 days. The 0.45-g transmitters were attached using methods described by Burkepile et al. (2002) and Dreitz et al. (2011).

A second capture took place when broods reached 4-6 weeks old (juveniles). Broods were located approximately $2 \mathrm{~h}$ before sunrise using radio-telemetry and a FLIR Thermal Imaging Camera i ${ }^{\circledR}$. Following location, broods were spotlighted and captured with a 120-cm-diameter hoop-net attached to a $2.25-\mathrm{m}$ pole. After capture, the 0.45-g transmitters were removed if present, and juveniles were fitted with either a 1.7-g expandable necklace-style transmitter (American Wildlife Enterprises, Monticello, FL) or a 1-g suture-style transmitter (Advanced Telemetry Systems, Isanti, MN). Both transmitters had an expected battery life between 51 and 80 days. Additional juvenile broods were added to the study through opportunistic captures using Stoddard funnel traps (Stoddard 1931). These broods were aged based upon plumage characteristics and mass at capture (Smith and Cain 1984, Lusk et al. 2005). Due to incomplete brood captures and resource limitations, not all of the chicks or juveniles within broods were radio-tagged. Broods were released immediately following radiotransmitter attachment.

Following capture, chick broods were tracked 5-7 days per week and juvenile broods were tracked 5 days per week. If a marked chick was farther than $100 \mathrm{~m}$ from a brooding adult, chicks were flushed to determine whether mortality had occurred or whether an amalgamation event had taken place. If a chick or juvenile transmitter signal could not be located, we searched extensively for it within a minimum radius of $2 \mathrm{~km}$ of the last known brood location. Our maximum recorded daily movement for broods was about $1.6 \mathrm{~km}$ (Orange 2015), and it was unlikely that an individual's daily movement would exceed this distance. If a signal was not located within this search area, we recorded the individual as a mortality. To minimize disturbance, broods were only flushed when all radio-tagged individuals within the brood had died. When radio-tagged individuals were no longer present with a brooding adult, broods were flushed weekly to verify the presence of at least one chick or juvenile. If brooding adults were found without chicks or juveniles during this flush verification, we would conduct a nightly roost count with a FLIR Thermal Imaging Camera i ${ }^{\circledR}$ using the methodology described by Andes et al. (2012) to verify brood failure. We estimated brood survival using the conservative designation of a successful brood as one having at least one surviving chick (Fields et al. 2006, Goddard and Dawson 2009, Matthews et al. 2011, LeBeau et al. 2014, Pollentier et al. 2014).

\section{Data Analysis}

To evaluate the flush method, we used data collected from radio-tagged chicks and juveniles (which were present in all broods) to generate estimates of brood survival. We estimated brood survival of our sample of broods using 2 analysis methods: (1) the telemetry method in which we used radio-tagged chicks or juveniles within a brood to estimate brood survival, defined as survival of at least one radio-tagged individual, even if it was no longer with the original brooding adult, and (2) the flush method in which brood survival was based on the presence of at least one individual with a brooding adult at the end of the weekly sampling interval. Each sample of broods was analyzed using both telemetry 
and flush methodologies. Telemetry brood survival estimates accommodate amalgamations facilitated by brood abandonment or adult mortality because they are based upon the survival of at least one radio-tagged chick or juvenile, even if it was not with the original brood adult. It is important to note that we define brood survival differently depending on the analysis method. For example, if a brooding adult dies between the first and second weekly sample intervals and the radiotagged individuals join another brood, then we would consider the brood a failure at the second interval when using the flush method, but would consider it successful when using the telemetry method.

The 3-week-chick and 5-week-juvenile period brood survival was calculated using the Kaplan-Meier product limit estimator (Kaplan and Meier 1958). We defined the day of capture as day 0 for all broods regardless of capture date. For the rare situation (i.e., only 4 occurrences) in which 2 radio-tagged brooding adults were present in a brood, we included only incubating adults in our analysis. We used $Z$ tests (Pollock et al. 1989) to compare the Kaplan-Meier brood survival estimates produced by the telemetry and flush analysis methods for bobwhite and Scaled Quail at the chick and juvenile life stages. In order to avoid type II errors resulting from small sample sizes, alpha levels were set at 0.10 .

\section{RESUlts}

During the study, we attached transmitters to 191 chicks (99 bobwhite and 92 Scaled Quail) within 45 broods (26 bobwhite and 19 Scaled Quail), and 100 juveniles (51 bobwhite and 49 Scaled Quail) within 22 broods (11 bobwhite and 11 Scaled Quail). Within chick broods, radio-tagged chicks accounted for 75\%-100\% of the chicks in 28 broods, $50 \%-75 \%$ of the chicks in 6 broods, $25 \%-50 \%$ of the chicks in 5 broods, and $16.7 \%-25 \%$ of the chicks in 6 broods. Within juvenile broods, radio-tagged juveniles accounted for $75 \%-100 \%$ of the juveniles in 8 broods, $50 \%-75 \%$ of the juveniles in 7 broods, $25 \%-50 \%$ of the juveniles in 4 broods, and $12.5 \%-25 \%$ of the juveniles in 3 broods.

We found that brood survival estimates for the telemetry method were greater than those for the flush method at both the chick (teleme- try, 0.808 [SE 0.077]; flush, 0.500 [SE 0.098]; $Z=2.665, P=0.004)$ and juvenile life stages (telemetry, 0.636 [SE 0.145]; flush, 0.364 [SE 0.145]; $Z=1.453, P=0.073)$ in bobwhites. The percentage of bobwhite broods that were considered successful was greater for the telemetry method than for the flush method by $30.8 \%$ at the chick life stage and $27.3 \%$ at the juvenile life stage. For Scaled Quail, Kaplan-Meier brood survival estimates were similar between methodologies at both the chick (telemetry, 0.842 [SE 0.084]; flush, 0.789 [SE 0.094]; $Z=0.446, P=0.328)$ and juvenile (telemetry, 0.818 [SE 0.116]; flush, 0.818 [SE 0.116]; $Z=0, P \geq 0.999)$ life stages. At the chick life stage, the percentage of Scaled Quail broods that were successful differed by only $5.3 \%$ between methodologies. Differences in bobwhite brood survival estimates between the 2 analysis methodologies were attributed to brood abandonments $(n=4)$ in $15.4 \%$ of chick broods and brooding adult mortality $(n=9)$ in $36.4 \%$ of juvenile broods and $19.2 \%$ of chick broods. Overall, brood abandonment and brooding adult mortality accounted for discrepancies in $29.7 \%$ of total bobwhite broods monitored. For Scaled Quail, we only recorded one occurrence of brood abandonment and one occurrence of brooding adult mortality, which may explain why the brood survival estimates were similar.

\section{Discussion}

In our study, we observed divergence between the telemetry and flush brood survival estimates at both the chick and juvenile life stages in bobwhites, with the telemetry estimates being greater in both life stages. Consequently, it appears that flush counts produce brood survival estimates that are biased low for bobwhites. The differences between the 2 analysis methods were primarily a result of brood abandonment and death of the brooding adult. In contrast, we did not observe a significant difference between the 2 methods in Scaled Quail for either life stage. With fewer brooding adults suffering mortalities and fewer brood abandonments occurring during the monitoring period, Scaled Quail brood survival estimates appeared less biased compared to bobwhite brood survival estimates.

Brood amalgamation resulting from brood abandonment was a leading cause of disparities 
in bobwhite brood survival estimates between telemetry and flush methodologies. We observed radio-tagged bobwhite brooding adults permanently abandoning their broods on 4 occasions, with adults leaving their chicks in the care of another brood or a large gang-brood. It has been well documented in quail species that brooding adults occasionally abandon chicks in an effort to renest (Gullion 1956, Francis 1965, Curtis et al. 1993, Suchy and Munkel 1993), especially early in the breeding season when hens have ample opportunity to renest (Sermons and Speake 1987). Consequently, brood survival estimates may be biased low because the flush count methodology typically, and often mistakenly, assumes that chicks within a brood suffered mortality following brood abandonment.

In addition to brood abandonment, death of the brooding adult was a common cause of disparities in bobwhite brood survival estimates between flush and telemetry methodologies. Throughout the chick and juvenile observation periods, a total of 9 bobwhite brooding adults died. When a brooding adult died, the remaining offspring either amalgamated into another brood located in close proximity, or primary care was transferred to a secondary brooding adult that had not been radio-tagged. In numerous gallinaceous species, adult survival rates during the breeding season are highly variable, ranging from quite low for some species $(0.22-0.80$ for Scaled Quail [Rollins et al. 2009] and 0.33 for bobwhites [Burger et al. 1995a]) to moderate for other species ( 0.56 for Ring-necked Pheasant [Phasianus colchicus; Synder 1985] and 0.68 for Lesser Prairie-Chicken [Tympanuchus pallidicinctus; Hagen et al. 2007]). As our results show, offspring do not necessarily suffer a similar fate when a brooding adult dies. Precocial gallinaceous chicks readily amalgamate into other broods if their brooding adult suffers mortality (Dahlgren et al. 2010b). When conducting flush counts, researchers should be aware that the death of a brooding adult can result in brood survival estimates that are biased low. Researchers may reduce biases that result from brooding adult mortality by censoring broods whose adults have died during the monitoring period.

Although differences in survival estimates between flush and telemetry methodologies in bobwhite broods were noted, these differences were not observed in Scaled Quail. Throughout our study, brooding adult mortality and abandonment were more common in bobwhites than in Scaled Quail at both the chick and juvenile life stages. The higher incidence of adult mortality and brood abandonment observed in bobwhites resulted in greater variations in survival estimates between methodologies within this species. Breeding season survival rates of Scaled Quail are reported to be slightly higher than those of bobwhites within the same latitude (Rollins et al. 2009). The higher survival rates of Scaled Quail likely reduced the impacts of adult mortality on brood survival estimates.

Furthermore, while brood abandonments were commonly observed in bobwhites during the 3-week chick monitoring period, Scaled Quail females commonly abandoned their broods to the care of the putative father early in the nesting season when hens would have had ample opportunity to renest. We were unable to document this conclusively, as transmitters could only be fitted to chicks when they reached 7-11 days old; however, based upon daily observations using radio-telemetry, abandonment likely occurred with at least $40 \%$ of the incubating adults that hatched nests throughout the 2013 and 2014 breeding seasons (Orange 2015). Brood abandonment by females into the care of putative fathers is not unique to Scaled Quail, as it has been documented in the closely related California Quail (Francis 1965) and Gambel's Quail (Gullion 1956), and in other quail and socially monogamous grouse species (Schemnitz 1961, Anthony 1970, Martin and Cooke 1987, Curtis et al. 1993, Burger et al. 1995b). During early stages of brood rearing, biparental care in combination with brood abandonment of the radio-tagged adult, may bias brood survival estimates in a similar manner as brooding adult mortality. If we had included brood survival estimates from hatch to 7-11 days old, our Scaled Quail survival estimates may have showed greater divergence between the flush and telemetry analysis methods. For quail and socially monogamous grouse species that exhibit biparental care, it may benefit researchers to radio-tag both male and female brooding adults during early brood-rearing stages.

Within our study, transmitters were not attached to all individuals within each brood. Consequently, it is possible that observed 
differences between telemetry and flush survival estimates were a conservative difference. For example, it is possible that broods with a low proportion of the offspring radio-tagged had at least one surviving individual that was not radio-tagged. If we had been able to radiotag all the offspring with a brood at capture, the observed differences between methodologies may have been greater. Additionally, because we were not able to radio-tag all of the individuals within each brood, we were unable to account for biases that may have resulted from other forms of amalgamations, primarily adoptions into a monitored brood. Due to difficulties in accounting for biparental and communal brooding, it was impossible to quantify adoption rates. Adoptions may have influenced the flush survival estimates because this form of amalgamation would have led us to believe that a brood was successful, even though it is possible that individuals remaining within the brood were adopted. However, it was rare for all of the radio-tagged individuals within a brood to suffer mortality while offspring were still present with a brooding adult. In fact, this was only observed in 3 of 67 broods monitored, and this primarily occurred within broods in which we had radio-tagged $\leq 25 \%$ of the individuals during the capture event. Furthermore, though the flush analysis method mimicked the flush count methodology, broods were only flushed (on a weekly basis) when there were no longer radio-tagged individuals within broods. By not flushing a brood with at least one surviving radio-tagged individual, we assumed that there was a $100 \%$ probability that at least one individual could be detected within the brood. This assumption may be unrealistic when using a flush count technique; however, many studies verify brood failure similarly during multiple sampling occasions or with a combination of flush and nocturnal roost counts (Pitman et al. 2006, Pleasant et al. 2006). Finally, although brooding adult mortality and abandonment were common with bobwhites at our study site, we recognize that rates of brooding adult mortality and abandonment are likely highly variable throughout the bobwhite distribution, and as such, these factors may influence other brood survival estimates differently than they influenced our results.

In conclusion, estimates of brood survival using flush count methods may be inherently biased. We suggest that researchers and wildlife managers consider the limitations of data collected from flush counts and adapt their sampling protocols appropriately. For gallinaceous species that suffer high levels of brooding adult mortality or brood abandonment, brood survival estimates generated from flush counts may be useful as an estimate of relative recruitment, to be compared between years, sites, and treatment units, but they may not be suitable to estimate brood survival or to conduct population viability analysis. Finally, we suggest that future work should investigate the impact that other forms of amalgamation (i.e., adoptions, communal brooding, and gang-brooding) may have on brood survival estimates.

\section{ACKNOWLEDGMENTS}

Capture and handling protocols were reviewed and approved by Oklahoma State University's Institutional Animal Care and Use Committee (ACUP \#AG-13-2 and ACUP \#AG-11-22). Funding was provided by the Pittman-Robertson Federal Aid to Wildlife Restoration Act under project W-161-R (F11AF00069) of the Oklahoma Department of Wildlife Conservation and Oklahoma State University, administered through the Oklahoma Cooperative Fish and Wildlife Research Unit (Oklahoma Department of Wildlife Conservation, Oklahoma State University, U.S. Geological Survey, U.S. Fish and Wildlife Service, and the Wildlife Management Institute cooperating). We thank J. Groendyke for providing the Groendyke Research Assistantship. Additionally, we thank D.M. Leslie Jr., R.A. Van Den Bussche, and anonymous referees for reviewing an earlier draft of this manuscript. Finally, we thank all of our hardworking technicians for their assistance with this project.

\section{Literature Cited}

Andes, A.K., B.R. Buckley, T.L. Warken, P.C. WoOds, S.R Yancey, And C.B. Dabbert. 2012. Use of a thermal camera to aid in capturing Northern Bobwhite quail chicks. Wildlife Society Bulletin 36:371-375.

AnTHony, R. 1970. Ecology and reproduction of California Quail in south eastern Washington. Condor 72:276-287.

Brooks, J.L., AND D. Rollins. 2007. Gang-brooding in Northern Bobwhites in West Texas. Wilson Journal of Ornithology 119:137-138.

Burger, L.W., T.V. Dailey, E.W. KurZejeski, and M.R. RYAN. 1995a. Survival and cause-specific mortality of 
Northern Bobwhites in northern Missouri. Journal of Wildlife Management 59:401-410.

Burger, L.W., M.R. Ryan, T.V. Dailey, and E.W. KurzeJESKI. 1995b. Reproductive strategies, and mating systems of Northern Bobwhite in Missouri. Journal of Wildlife Management 59:417-426.

Burkepile, N.A., J.W. Conelly, D.W. Stanley, and K.P. REESE. 2002. Attachment of radiotransmitters to one-day-old sage-grouse chicks. Wildlife Society Bulletin 30:93-96.

Curtis, P.D., B.S. Mueller, P.D. Doerr, C.F. Robinette, AND T. DeVos. 1993. Potential polygamous breeding behavior in Northern Bobwhite. Proceedings of the National Quail Symposium 3:55-63.

Dahlgren, D.K., T.A. Messmer, and D.N. Koons. 2010 b. Achieving better estimates of Greater Sage-Grouse chick survival in Utah. Journal of Wildlife Management 74:1286-1294.

Dahlgren, D.K., T.A. Messmer, E.T. Thacker, and M.R GUTTERY. 2010a. Evaluation of brood detection techniques: recommendations for estimating Greater Sage-Grouse productivity. Western North American Naturalist 70:233-237.

DeMaso, S.J., A.D. Peoples, S.A. Cox, and E.S. Parry. 1997. Survival of Northern Bobwhite chicks in western Oklahoma. Journal of Wildlife Management 61:846-853.

Dreitz, V.J., L.A. Baeten, T. Davis, and M.M. Riordan. 2011. Testing radiotransmitter attachment techniques on Northern Bobwhite and Chukar chicks. Wildlife Society Bulletin 35:475-480.

Faircloth, B.C., W.E. Palmer, and J.P. Carroll. 2005. Post-hatching brood amalgamation in Northern Bobwhites. Journal of Field Ornithology 76:175-182.

Fields, T.L., G.C. White, W.C. Gilbert, and R.D. RoDGERs. 2006. Nest and brood survival of Lesser Prairie-Chickens in west central Kansas. Journal of Wildlife Management 70:931-938.

Francis, W.J. 1965. Double broods in California Quail. Condor 67:541-542.

GodDard, A.D., AND R.D. Dawson. 2009. Factors influencing the survival of neonate Sharp-tailed Grouse Tympanuchus phasianellus. Wildlife Biology 15: $60-67$.

Godfrey, G.A. 1975. Underestimation experienced in determining Ruffed Grouse brood size. Journal of Wildlife Management 39:191-193.

Gonzalez, M.J., H.B. Quigley, and C.I. Taylor. 1998. Habitat use and reproductive ecology of the Ocellated Turkey in Tikal National Park, Guatemala. Wilson Bulletin 110:505-510.

Gregg, M.A., M.R. Dunbar, and J.A. Crawford. 2007. Use of implanted radiotransmitters to estimate survival of Greater Sage-Grouse chicks. Journal of Wildlife Management 71:646-651.

Gullion, G.W. 1956. Evidence of double-brooding in Gambel's Quail. Condor 58:232-239.

Hagen, C.A., J.C. Pitman, B.K. Sandercock, R.J. Robel, AND R.D. Applegate. 2007. Age-specific survival and probable causes of mortality in female Lesser Prairie-Chickens. Journal of Wildlife Management 71:518-525.

Kaplan, E.L., AND P. Meier. 1958. Nonparametric estimation for incomplete observations. Journal of the American Statistical Association 53:457-481.

KepPIE, D.M. 1977. Inter-brood movements of juvenile Spruce Grouse. Wilson Bulletin 89:67-72.
LeBeau, C.W., J.L. Beck, G.D. Johnson, and M.J. HolLORAN. 2014. Short-term impacts of wind energy development on Greater Sage-Grouse fitness. Journal of Wildlife Management 78:522-530.

LotT, D.F., AND S.N.K. Mastrup. 1999. Facultative communal brood rearing in California Quail. Condor 101:678-681.

Lusk, J.J., F.S. Guthery, S.A. Cox, S.J. DeMaso, and A.D. PEOPLES. 2005. Survival and growth rate of Northern Bobwhite chicks in western Oklahoma. American Midland Naturalist 153:389-395.

Martin, K., AND F. COOKE. 1987. Bi-parental care in Willow Ptarmigan: a luxury? Animal Behavior 35:369-379.

Matthews, T.W., A.J. Tyre, J.S. TaYlor, J.J. Lusk, and I.A. Powell. 2011. Habitat selection of Greater Prairie-Chickens. Pages 179-191 in B.K. Sandercock, K. Martin, and G. Segelbacher, editors, Ecology, conservation, and management of grouse. University of California Press, Berkeley, CA.

Maxson S.J. 1978. Evidence of brood adoption by Ruffed Grouse. Wilson Bulletin 90:132-133.

McNew, L.B., A.J. Gregory, S.M. Wisely, and B.K. SANDERCOCK. 2012. Demography of Greater PrairieChickens: regional variation in vital rates, sensitivity values, and population dynamics. Journal of Wildlife Management 76:987-1000.

Metz, S.T., K.B. Melton, R. Aguirre, B.A. Collier, T.W. Schwertner, M.J. Peterson, and N.J. Silvy. 2006. Poult adoption and nest abandonment by a female Rio Grande Wild Turkey in Texas. Wilson Journal of Ornithology 118:259-261.

Musil, D.D., AND J.W. Connelly. 2009. Survival and reproduction of pen-reared vs translocated pheasants Phasianus colchicus. Wildlife Biology 15:80-88.

Oklahoma Climatological Survey. 2012. The climate of Beaver County. Norman, OK; [accessed 28 September 2014]. http://www.ocs.ou.edu

ORANGE, J.P. 2015. Breeding behavior, brood habitat use, and chick survival of two sympatric quail species at the periphery of their distributions. Master's thesis, Oklahoma State University, Stillwater, OK.

Orange, J.P., C.A. Davis, R.D. Elmore, and S.D. FuhLENDORF. 2016. Temporary communal brooding in Northern Bobwhite and Scaled Quail broods. Western North American Naturalist 76:122-127.

Palmer, W.E., K.M. Pickett, J.R. Anderson, and P.T. Bromley. 1998. Effects of foliar insecticides on survival of Northern Bobwhite chicks. Journal of Wildlife Management 62:1565-1573.

Pitman, J.C., C.A. Hagen, B.E. Jamison, R.J. Robel, T.M. Loughlin, and R.D. Applegate. 2006. Survival of juvenile Lesser Prairie-Chicken in Kansas. Wildlife Society Bulletin 34:675-681.

Pleasant, G.D., C.B. Dabbert, and R.B. Mitchell. 2006. Nesting ecology and survival of Scaled Quail in the Southern High Plains of Texas. Journal of Wildlife Management 70:632-640.

Pollentier, C.D., R.S. Lutz, and S.D. Hull. 2014. Survival and productivity of Eastern Wild Turkey females in contrasting landscapes in Wisconsin. Journal of Wildlife Management 78:985-996.

Pollock, K.H., S.R. Winterstein, C.M. Bunck, AND D.P.D. CuRTIS. 1989. Survival analysis in telemetry studies: the staggered entry design. Journal of Wildlife Management 59:137-142.

Rollins, D., B.D. TaYlor, T.D. Sparks, R.J. Buntyn, S.E. Lerich, L.A. Harveson, T.E. Wadell, and C.B. 
ScOTT. 2009. Survival of female Scaled Quail during the breeding season at 3 sites in the Chihuahuan Desert. Gamebird 2006: Quail VI and Perdix XII, 31 May-June 4 2006. Warnell School of Forestry and Natural Resources, Athens, GA.

Schemnitz, S.D. 1961. Ecology of the Scaled Quail in the Oklahoma Panhandle. Wildlife Monographs 8:3-47.

Sermons, W.O., and D.W. Speake. 1987. Production of second broods in Northern Bobwhite. Wilson Bulletin 99:285-286.

Smith, D.S., AND J.R. CAIN. 1984. Criteria for age classification of juvenile Scaled Quail. Journal of Wildlife Management 48:187-191.

Smith, M.D., A.D. Hammond, L.W. Burger JR., W.E. Palmer, A.V. Carver, and S.D. Wellendorf. 2003. A technique for capturing Northern Bobwhite chicks. Wildlife Society Bulletin 31:1054-1060.

Spears, B.L., W.B. Ballard, M.C. Wallace, R.S. Phillips, D.P. Holdstock, J.H. Brunjes, R.D. Applegate, M.S. Miller, and P.S. Gibson. 2005. Survival of Rio Grande turkey chicks. Journal of Field Ornithology 76:12-20.

Steen, J.B., AND O.A. Haugvold. 2009. Cause of death in Willow Ptarmigan Lagopus l. lagopus chicks and the effect of intensive, local predator control on chick production. Wildlife Biology 15:53-59.
StOdDard, H.L. 1931. The Bobwhite Quail: its habits, preservation, and increase. Charles Scribner's Sons, New York, NY.

Suchy, W.J., AND R.J. MunkeL. 1993. Breeding strategies of the Northern Bobwhite in marginal habitat. Proceedings of the National Quail Symposium 3:69-73.

SYNDER, W.D. 1985. Survival of radio-marked Ringnecked Pheasant in Colorado. Journal of Wildlife Management 49:1044-1050.

Tirpak, J.M., W.M. Giuliano, and C.A. Miller. 2008. Ruffed Grouse brood habitat selection at multiple scales in Pennsylvania: implications for survival. Canadian Journal of Zoology 86:329-337.

Tirpak, J.M., W.M. Giuliano, C.A. Miller, T.J. Allen, S. BitTNer, D.A. Buehler, J.W. Edwards, C.A. Harper, W.K. Igo, G.W. Norman, ET AL. 2006. Ruffed Grouse population dynamics in the central and southern Appalachians. Biological Conservation 133:364-378.

Wong, M.M.L., B.C. Fedy, S. Wilson, and K.M. Martin. 2009. Adoption in Rock and White-tailed Ptarmigan. Wilson Journal of Ornithology 121:638-641.

Received 13 April 2016 Accepted 3 October 2016 